\title{
Adsorption and desorption of 2,4,6-trichlorophenol onto and from ash as affected by $\mathrm{Ag}^{+}, \mathrm{Zn}^{2+}$, and $\mathrm{Al}^{3+}$
}

\author{
Guangcai Chen • Yusheng Wang • Zhiguo Pei
}

Received: 6 June 2013 / Accepted: 29 August 2013 / Published online: 10 September 2013

(C) Springer-Verlag Berlin Heidelberg 2013

\begin{abstract}
Metal cations and organic pollutants mostly co-exist in the natural environment. However, their interactions in adsorption processes have yet to be adequately addressed. In the current study, the effect of inorganic cations with different charges $\left(\mathrm{Ag}^{+}, \mathrm{Zn}^{2+}\right.$, and $\left.\mathrm{Al}^{3+}\right)$ on the adsorption and desorption of 2,4,6-trichlorophenol (TCP) onto and from processed ash derived from wheat (Triticum aestivum L.) straw was investigated. The adsorption and desorption of TCP were both nonlinear; the isotherm and kinetics curves fitted well using the Freundlich equation and a pseudo-second-order model, respectively. The presence of $\mathrm{Ag}^{+}$promoted TCP adsorption, while $\mathrm{Zn}^{2+}$ and $\mathrm{Al}^{3+}$ reduced TCP adsorption onto ash. The desorption of TCP from ash showed obvious hysteresis, and the presence of $\mathrm{Ag}^{+}, \mathrm{Zn}^{2+}$, and $\mathrm{Al}^{3+}$ caused the desorption to be less hysteretic. The suppression of TCP adsorption by $\mathrm{Zn}^{2+}$ and $\mathrm{Al}^{3+}$ was ascribed to the partial overlapping of adsorption groups between TCP and metal ions. $\mathrm{Al}^{3+}$ had a stronger inhibition effect than that of $\mathrm{Zn}^{2+}$ due to its higher binding capacity and larger hydrated ionic radius than those of $\mathrm{Zn}^{2+}$. Enhanced adsorption of TCP onto ash by $\mathrm{Ag}^{+}$was ascribed to its ability to reduce the competitive adsorption of water molecules on ash surface by replacing the original ions, such as $\mathrm{Na}^{+}$ and $\mathrm{Ca}^{2+}$, and compressing the hydrated ionic radius of these metal ions. In addition, $\mathrm{Ag}^{+}$was able to bind with the aromatic organic compounds containing $\pi$-electrons, which resulted in a further increase of TCP adsorption by ash.
\end{abstract}

Responsible editor: Philippe Garrigues

G. Chen $(\square)$

Research Institute of Subtropical Forestry, Chinese Academy of Forestry, Fuyang, Zhejiang 311400, China

e-mail: guangcaichen@sohu.com

Y. Wang $\cdot$ Z. Pei

State Key Laboratory of Environmental Chemistry and Ecotoxicology, Research Center for Eco-Environmental Sciences, Chinese Academy of Sciences, Beijing 100085, China
Keywords Adsorption $\cdot$ Ash $\cdot 2,4,6$-Trichlorophenol $\cdot \mathrm{Ag}^{+}$. $\mathrm{Zn}^{2+} \cdot \mathrm{Al}^{3+}$

\section{Introduction}

Plant stalks and other residues left after crops have been harvested are burned in situ in many countries and areas of the world. Ash resulting from such burning may greatly increase the black carbon (BC) content in agricultural soil (Naidu et al. 1998). BC in soils and sediments plays important roles in the adsorption of neutral organic contaminants through the well-known mechanism of contaminant partitioning with soil/ sediment organic matter (Wang et al. 2009). Ash has a porous rigid structure and large surface area, meaning it is an effective adsorbent for hydrophobic organic compounds and can seriously affect their fate in the environment (Yang and Sheng 2003; Dilip et al. 2006; Srivastava et al. 2005). For example, Toth et al. (1999) found that soil that has experienced kangaroo grass burning exhibits significantly reduced diuron plant toxicity. Meanwhile, research on crop-residue-derived chars suggests that pyrolysis-derived charcoal adsorption of neutral organic contaminants takes place almost exclusively as surface adsorption, while low-temperature decomposition-derived charcoal adsorption is characterized mainly by surface adsorption, but also accompanied by distribution (Chun et al. 2004).

2,4,6-TCP (TCP) is a pollutant whose control is considered a high priority by the US Environmental Protection Agency (USEPA), as well as in China (Keith and Telliard 1979; Zhou et al. 1991), as it can result in lymphoma, leukemia, and liver cancer through oral exposure in animals (Wang et al. 2005). It is often found in emissions from fossil fuel combustion, municipal waste incineration, and chlorination of water containing phenol or certain aromatic acids with hypochlorite, or during the disinfection of water (Chaliha and Bhattacharyya 2008). TCP has also been widely used as a preservative, pesticide, and antibacterial agent, which can then be released into the water system from soil, thus causing poisoning of the ecosystem. 
Therefore, the adsorption and desorption of TCP onto and from soil and soil components are important to understand its migration behavior in the environment. Cea et al. (2005), through a study based on soil from southern Chile, suggested that the formation of inner- and outer-sphere complexes between deprotonated molecules and active sites in soil are the main sorption mechanisms for chlorophenols, and that chlorophenol sorption in neutral form could be induced by hydrogen bond formation between the phenolic hydroxyl group and the neutral surface, followed by ligand exchange with consequent deprotonation. Kung and McBride (1991) reported that TCP adsorption by $\mathrm{Fe}$ and $\mathrm{Al}$ oxides is realized through inner complex formation, while Wang et al. (2005) found that TCP adsorption by humic acid-modified montmorillonite and illite is greater than by either mineral its pure form. More recently, Wang et al. (2009) suggested that TCP adsorption on wheat ash can be ascribed to surface adsorption and concurrent partitioning into the residual organic matter phase.

Carbonaceous materials, including ash, are also effective adsorbents in removing heavy metals (e.g., $\mathrm{As}^{5+}, \mathrm{Cd}^{2+}, \mathrm{Cr}^{6+}$, $\mathrm{Cu}^{2+}, \mathrm{Hg}^{2+}, \mathrm{Pb}^{2+}$, and $\mathrm{Zn}^{2+}$ ) from the aqueous phase (Chen et al. 2009; Seco-Reigosa et al. 2013; Shah et al. 2013; Wang et al. 2009, 2011). It is common in many contaminated sites to find a complex suite of organic chemicals and inorganic elements in existence together (Sprovieri et al. 2007), and the coexistence of metal ions affects the adsorption of organic contaminants to charcoal, ash, and carbon nanotubes (Chen et al. 2007, 2009; Wang et al. 2009, 2011). Chen et al. (2007) found that $\mathrm{Cu}^{2+}$ decreases the adsorption of 2,4-dichlorophenol, 1,2-dichlorobenzene, and naphthalene by $30-60 \%$, while $\mathrm{Ag}^{+}$increases adsorption of these solutes by wood charcoal. Wang et al. (2011) suggested that $\mathrm{Cu}^{2+}, \mathrm{Pb}^{2+}$, and $\mathrm{Zn}^{2+}$ diminish $p$-nitrophenol adsorption on ash, while increasing its desorption remarkably.

To our knowledge, the effect of metal cations with different charges on the adsorption of organic chemicals by ash or BC has not been adequately investigated. It should be realized that metal cations and TCP may occur together in the field, especially in soil irrigated by wastewater in countries with high levels of water shortage (Daughney and Fein 1997; Mueller et al. 1989). In the current reported study, metal cations with different charges, such as $\mathrm{Ag}^{+}, \mathrm{Zn}^{2+}$, and $\mathrm{Al}^{3+}$, were selected because they are abundant in the environment and occur widely in soil and water. The specific aim of the study was to examine how $\mathrm{Ag}^{+}, \mathrm{Zn}^{2+}$, and $\mathrm{Al}^{3+}$ affect the adsorption of TCP onto ash, and the desorption from it.

\section{Materials and methods}

\section{Materials}

TCP with purity $>98 \%$ was purchased from Aldrich Chemical Co. Inc. It had a $\log K_{\text {ow }}$ of $3.67, \mathrm{p} K_{\mathrm{a}}$ of 6.1 , and a water solubility Cs of $300 \mathrm{mg} \mathrm{L}^{-1}(\mathrm{pH}<5$; Wightman and Fein 1999). $\mathrm{AgNO}_{3}, \mathrm{Zn}\left(\mathrm{NO}_{3}\right)_{2}$, and $\mathrm{Al}\left(\mathrm{NO}_{3}\right)_{3}$ were of guaranteed reagent grade, while other chemicals were of analytical reagent grade or better.

Raw ash was obtained by burning air-dried wheat (Triticum aestivum L.) straw on a stainless steel plate $(1 \times 1 \mathrm{~m})$ in an open field under uncontrolled natural conditions (Yang and Sheng 2003). The ash was then ground into powder and sieved $(1 \mathrm{~mm})$. One gram of raw ash was treated with $40 \mathrm{~mL} \mathrm{1-M} \mathrm{hydrochloric} \mathrm{acid} \mathrm{for} 4 \mathrm{~h}$ and then centrifuged at $2,000 \times g$ for $20 \mathrm{~min}$ and the supernatant discarded. The process was repeated four times, and then treated with a mixture of hydrochloric acid and hydrofluoric acid (0.1:0.3 mol/L) four times, followed by thorough washing with distilled water to remove soluble salts and silicon. Processed ash was dried overnight at $80^{\circ} \mathrm{C}$ and sealed for storage.

Characteristics of the processed ash were determined as follows. The total content of $\mathrm{C}, \mathrm{H}$, and $\mathrm{N}$ were determined using a CHN Elemental Analyzer (Vario EL III Elementar, Germany), and the ash content was determined by combustion of the processed ash at $750{ }^{\circ} \mathrm{C}$ for $4 \mathrm{~h}$. Oxygen content was calculated by mass difference [Oxygen content $=100 \%-(\mathrm{C}$ content $+\mathrm{H}$ content $+\mathrm{N}$ content + ash content)]. Specific surface area was measured with nitrogen at $77 \mathrm{~K}$ with an ASAP2020 instrument (Micromeritics Instrument Corporation, USA) and calculated using the Brunauer-Emmett-Teller equation. The group distribution was measured using a 300-MHz NMR spectrometer (Varian INOVA 300) CPMAS ${ }^{13} \mathrm{C}$ NMR. A summary of the characteristics of the processed ash is provided in Table 1.

\section{Batch adsorption and desorption}

The processed ash was applied in all the following batch adsorption and desorption experiments. Ten milligrams of processed ash were used for the adsorption of TCP. Ash was combined with the test solute(s) dissolved in 25-mL deionized water containing $0.01 \mathrm{~mol} \mathrm{~L}^{-1} \mathrm{NaNO}_{3}$ and $100 \mathrm{mg} \mathrm{L}^{-1} \mathrm{NaN}_{3}$ as a biocide in 40-mL screw-cap glass vials sealed with Teflon screw caps. All adsorption experiments were performed in triplicate. To evaluate the effect of $\mathrm{pH}$ on adsorption of TCP, solution $\mathrm{pH}$ was adjusted to $2.0-9.0$ with $0.1-\mathrm{M}^{\mathrm{HNO}} 3$ or $\mathrm{NaOH}$. In adsorption isotherms experiments, the concentrations of TCP ranged from $20 \%$ to $80 \%$ of its solubility, and the concentrations of the three metal cations were $0,0.01$, 0.05 , and $0.1 \mathrm{mM}$. The $\mathrm{pH}$ was adjusted to $4.5 \pm 0.1$ in adsorption kinetics and isotherm experiments, where dissolved TCP was predominantly ( $>99.3 \%$ ) neutral, and where hydrolysis and precipitation of $\mathrm{Ag}^{+}, \mathrm{Zn}^{2+}$, and $\mathrm{Al}^{3+}$ were negligible. This $\mathrm{pH}$ value is also typical of the $\mathrm{pH}$ of red soil in southern China. The vials were shaken at $100 \mathrm{rpm}$ in a shaker (HZQF160, China) at $20 \pm 0.5^{\circ} \mathrm{C}$, and an equilibration time of 7 days was used routinely. After centrifugation $(2,000 \times \mathrm{g}$ for $20 \mathrm{~min})$, 
Table 1 Physical and chemical properties of processed ash

\begin{tabular}{ll}
\hline Ash content (\%) & 1.66 \\
C content (\%) & 77.0 \\
N content (\%) & 0.56 \\
H content (\%) & 2.58 \\
O content (\%) & 18.2 \\
BET surface area ( $\left.\mathrm{m}^{2} \mathrm{~g}^{-1}\right)$ & 410 \\
Alkyl C (0-50 ppm) (\%) & 8.9 \\
$O$-alkyl C (50-110 ppm) (\%) & 6.9 \\
Aromatic C (110-145 ppm) (\%) & 73 \\
$O$-aryl C (145-163 ppm) (\%) & 9.0 \\
Carboxyl C (163-190 ppm) (\%) & 2.6 \\
Aliphatic C (\%) & 7.2 \\
Aromatic C (\%) & 90 \\
Aromaticity & 12.5 \\
Aliphaticity & 0.08 \\
POC & 0.182
\end{tabular}

${ }^{\mathrm{a}}$ Oxygen content $=100 \%-(\mathrm{C}$ content $+\mathrm{H}$ content $+\mathrm{N}$ content + ash content)

$P O C$ percentage of polar organic carbon, which was calculated from the peak areas listed above using the equation $\mathrm{POC}=(O$-alkyl $\mathrm{C}+O$-aryl $\mathrm{C}+$ carboxyl $\mathrm{C})($ alkyl $\mathrm{C}+O$-alkyl $\mathrm{C}+$ aromatic $\mathrm{C}+O$-aryl C + carboxyl C $) \times 100$

TCP in the liquid phase was determined by HPLC (HP 1100, Agilent Technologies).

Desorption experiments using a sequential decant-refill technique immediately followed the completion of the adsorption experiments. The desorption solution contained $0.01 \mathrm{M} \mathrm{NaNO}_{3}$ and $0.1 \mathrm{~g} \mathrm{~L}^{-1} \mathrm{NaN}_{3}$. The vials were also shaken at $100 \mathrm{rpm}$ in a shaker (HZQ-F160, China) at $20 \pm 0.5^{\circ} \mathrm{C}$, and a desorption time of 7 days was used routinely. After centrifugation $(2,000 \times g$ for $20 \mathrm{~min}$ ), $10 \mathrm{~mL}$ supernatant was removed and refilled with the same volume of fresh desorption solution. After the first desorption, TCP in solution after each desorption was determined, and the amounts of adsorption and desorption were calculated by measured concentrations. Desorption was conducted for three consecutive times, and the reaction $\mathrm{pH}$ was maintained at $4.5 \pm$ 0.1 during the whole process. In the desorption process, the adsorbate loss during the operation of supernatant removal and background solution addition was $<1 \%$ and negligible.

Blank experiments indicated that recoveries of adsorbates without ash were greater than $98 \%$ of their initial concentrations, suggesting no significant losses, degradation, or adsorption by the glass vials in the timeframe of the batch adsorption study. Therefore, the adsorbed mass was calculated by the difference between initial and final equilibrium concentrations.

\section{Analysis of TCP}

TCP in solution was determined by HPLC, which was equipped with a diode array detector at $220 \mathrm{~nm}$, with an extended polar

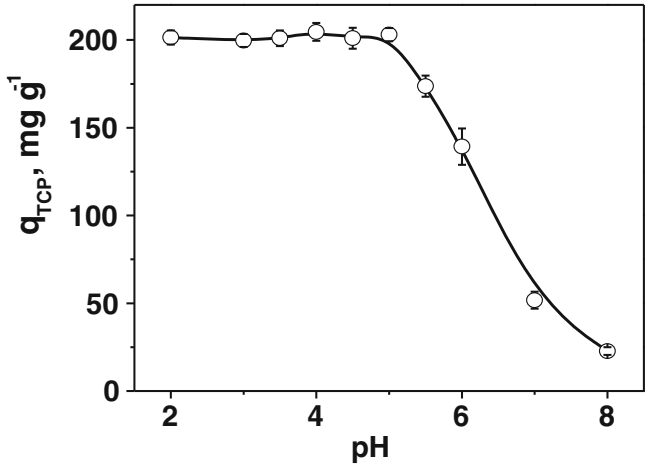

Fig. 1 Effect of $\mathrm{pH}$ on the adsorption of 2,4,6-TCP $\left(0.25 \mathrm{mg} \mathrm{L}^{-1}\right)$ by ash

selectivity reversed phase column of $\mathrm{C}_{18}(15 \mathrm{~cm} \times 4.6 \mathrm{~mm})$. Isocratic elution was performed at a flow rate of $1.0 \mathrm{~mL} \mathrm{~min}$ with a mobile phase of methanol/water (80:20\%).

Data analysis

Adsorption kinetics of TCP onto ash was analyzed with pseudo-first-order (Eq. 1) and pseudo-second-order kinetic models (Eq. 2; Ho and McKay 1998; Benguella and Benaissa 2002):

$\ln \left(q_{e}-q_{t}\right)=\ln q_{e}-k_{1} t$

$\frac{t}{q_{t}}=\frac{1}{k_{2} q_{e}{ }^{2}}+\frac{1}{q_{e}} t$

where $q_{e}$ and $q_{t}$ represent the TCP adsorption amount by ash at a balanced time or a certain time $t$ in units of milligrams per gram, and $k_{1}$ and $k_{2}$ are the adsorption rate constants of pseudo-first-order and pseudo-second-order kinetic models $\left(\mathrm{h}^{-1}, \mathrm{~g} \mathrm{mg}^{-1} \mathrm{~h}^{-1}\right)$. In the pseudo-first-order model, values of $q_{e}$ and $k_{1}$ could be obtained by the intercept and slope of the linear graph for $\ln \left(q_{e}-q_{t}\right)$ versus $t$. In the pseudo-secondorder model, $1 / q_{e}$ and $1 / k_{2} q_{e}{ }^{2}$ could be obtained by the intercept and slope of the linear graph for $\mathrm{t} / q$ versus $t$.

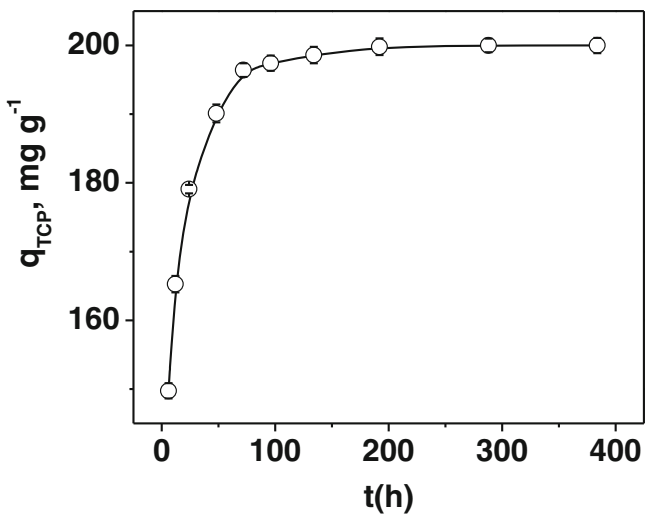

Fig. 2 Adsorption kinetics of 2,4,6-TCP $\left(0.25 \mathrm{mg} \mathrm{L}^{-1}\right)$ onto ash 
Fig. 3 Linear regressions of kinetics: (a) pseudo-first-order model; (b) pseudo-second-order model

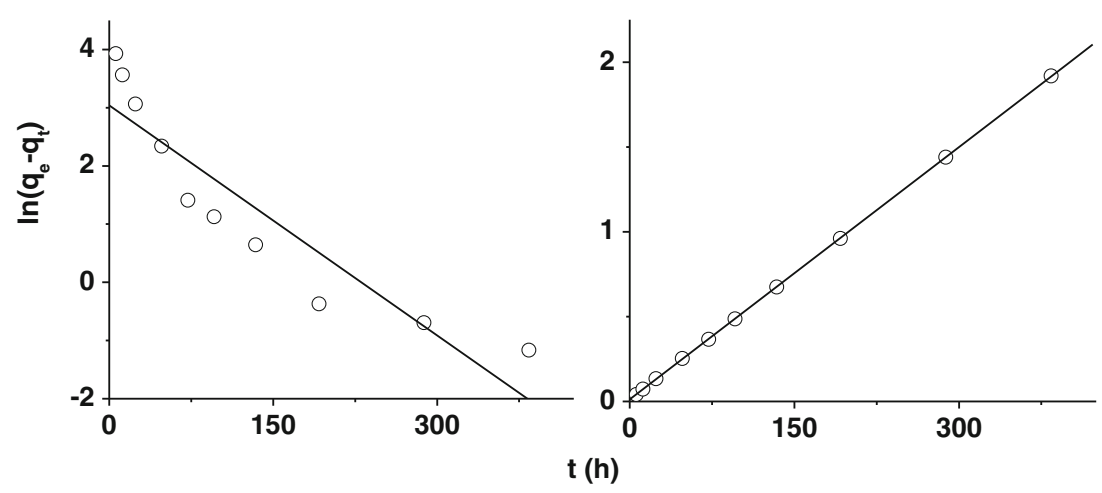

Adsorption isotherms of TCP were fitted with the Freundlich model (Eq. 3):

$Q=K_{f} C^{N}$,

where $Q$ and $C$ represent the adsorbed amount (milligrams per gram) and liquid phase equilibrium concentration (milligrams per liter), respectively. $K_{f}\left(\mathrm{mg}^{1-N} \mathrm{~g}^{-1} \mathrm{~L}^{N}\right)$ is the adsorption parameter, showing the adsorption capacity, and $N$ (dimensionless) is the Freundlich index, suggesting the degree of deviation of the isotherm from linearity.

The amount of TCP adsorbed $\left(q_{e}\right)$ was calculated using the following equation:

$q_{e}=\frac{\left(c_{\mathrm{i}}-c_{\mathrm{e}}\right) \nu}{m}$,

where $c_{\mathrm{i}}$ and $c_{\mathrm{e}}$ are the initial and equilibrium concentrations of TCP in milligrams per liter, $q_{e}$ is the amount adsorbed on the processed ash in milligrams per gram, $v$ is the volume of solution in liter, and $m$ is the total adsorbent mass in grams. Statistical analyses were performed using Origin 7.0 and SPSS 11.5.

\section{Results and discussion}

\section{Effect of $\mathrm{pH}$ on adsorption of TCP}

Solution $\mathrm{pH}$ can cause dissociation of surface groups of ash, thus affecting its surface charge density. In addition, $\mathrm{pH}$ is closely related to TCP protonation level. Therefore, the impact of $\mathrm{pH}$ on TCP adsorption was studied (Fig. 1). As shown in Fig. 1, TCP adsorption capacity remained stable at $\mathrm{pH} 2.0-5.0$ and decreased sharply at $\mathrm{pH}>5.0$. Considering the $\mathrm{p} K_{\mathrm{a}}$ value of 6.1 for TCP, the greater sorption at low pHs (3-5) may be ascribed to the predominant species of neutral TCP. An increase of solution $\mathrm{pH}$ of 5-8 increased the fraction of negatively charged TCP species and the dissociation of functional groups including hydroxyl, carboxyl, and other groups exposed on the adsorbent surface (Chen et al. 2009). Therefore, the repulsion of anionic TCP with the negatively charged surfaces of ash makes TCP sorption unfavorable. Furthermore, solubility of TCP increases rapidly when $\mathrm{pH}$ is above 6 (Wightman and Fein 1999). The increase in solubility decreases the driving force for sorption of TCP on ash.

\section{Effect of time on adsorption of TCP}

TCP adsorption by ash could be divided into two phases: the initial rapid adsorption stage and the subsequent slow adsorption stage (Fig. 2). TCP adsorption at the first stage could be ascribed to surface adsorption, while the second stage could be regarded as the diffusion process of TCP in ash pores. The diffusion may spread to a nearby region or micro-pore area, and the adsorption was very subtle at this stage. The adsorption of TCP reached apparent equilibrium in 3 days (Fig. 2). To achieve full adsorption, the balance time was set to 7 days in this study.

In order to better understand the adsorption kinetics of TCP on ash, pseudo-first-order and pseudo-second-order kinetic models were applied to fit and evaluate the experimental results (Ho and McKay 1998; Benguella and Benaissa 2002). The linear regression graph and fitting parameters are shown in Fig. 3 and Table 2. The pseudo-second-order kinetics model fitted the data very well $\left(R^{2}=1\right)$, with the standard deviation being significantly smaller than the pseudo-first-

Table 2 Pseudo-first-order and second-order constants

\begin{tabular}{llllll}
\hline & $\begin{array}{l}q_{e, \text { measured }} \\
\left(\mathrm{mg} \mathrm{g}^{-1}\right)\end{array}$ & $k$ & $\begin{array}{l}q_{e, \text { calculated }} \\
\left(\mathrm{mg} \mathrm{g}^{-1}\right)\end{array}$ & $R^{2}$ & $\mathrm{SD} \%$ \\
\hline $\begin{array}{c}\text { Pseudo-first-order } \\
\text { model }\end{array}$ & 200.19 & 0.013 & 20.88 & 0.924 & 73.41 \\
$\begin{array}{c}\text { Pseudo-second-order } \\
\text { model }\end{array}$ & 200.19 & 0.005 & 200 & 1 & 0.24 \\
\hline
\end{tabular}

$S D=\sqrt{\frac{\sum\left(q_{\text {measured }}-q_{\text {calculated }}\right)^{2}}{n-1}} \times 100$

$S D$ standard deviation 
Fig. 4 Adsorption of 2,4,6-TCP by ash in the absence and presence of $\mathrm{Ag}^{+}(\mathbf{a}), \mathrm{Zn}^{2+}(\mathbf{b})$, and $\mathrm{Al}^{3+}$ (c)

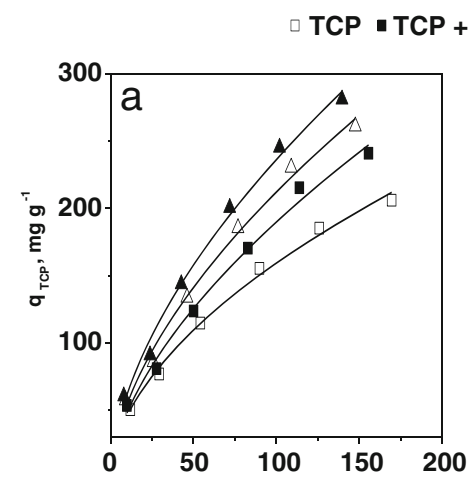

$\square \mathrm{TCP} \backsim \mathrm{TCP}+0.01 \mathrm{mM}^{\mathrm{n}+} \Delta \mathrm{TCP}+0.05 \mathrm{mM}^{\mathrm{n}+} \triangle \mathrm{TCP}+0.1 \mathrm{mM}^{\mathrm{n}+}$

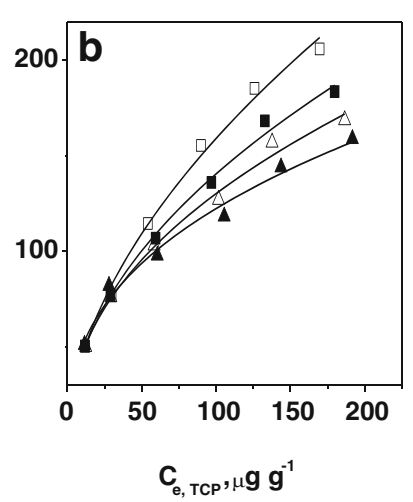

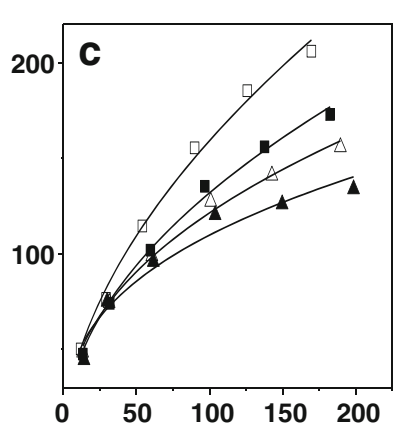

order kinetics model. In addition, the calculated $q$ value $\left(q_{e}\right.$, calculated) obtained through the pseudo-second-order kinetic model was closer to the measured data ( $q_{e}$, measured). Therefore, the adsorption kinetics of TCP on ash could be described by the pseudo-second-order kinetics model.

Effect of $\mathrm{Ag}^{+}, \mathrm{Zn}^{2+}$, and $\mathrm{Al}^{3+}$ on adsorption of TCP

The adsorption isotherm of TCP was nonlinear and could be fitted using the Freundlich equation (Fig. 4 and Table 3). The addition of metal cations showed different effects on the adsorption of TCP onto ash. The presence of $\mathrm{Ag}^{+}$enhanced TCP adsorption onto ash, and the promotion effect became more pronounced with the increase of $\mathrm{Ag}^{+}$initial concentrations. The presence of $\mathrm{Zn}^{2+}$ and $\mathrm{Al}^{3+}$ was able to inhibit TCP adsorption onto ash, and the suppression effects enhanced as the equilibrium concentration of $\mathrm{Zn}^{2+}$ and $\mathrm{Al}^{3+}$ in solution increased. With the same equilibrium concentration of metal ions, $\mathrm{Al}^{3+}$ showed stronger inhibition of TCP adsorption than $\mathrm{Zn}^{2+}$.

Metal cations and TCP may react with carboxyl, hydroxyl, and phenolic groups on ash, leading to competitive effects. Previous studies with X-ray absorption spectroscopy verified that $\mathrm{Zn}^{2+}$ could interact with the hydroxyl and carboxyl groups on the surface of ash, and Fourier-transformed spectroscopy suggests these groups on the adsorbent could form hydrogen bonds with TCP, thus leading to a partial overlapping of adsorption sites on ash (Wang et al. 2009, 2011). However, the binding of $\mathrm{Zn}^{2+}$ and these groups is stronger than the hydrogen bonding of TCP with them, and $\mathrm{Zn}^{2+}$ inhibits TCP adsorption through competing for the adsorption sites on the ash surface.

The competitive adsorption of $\mathrm{Al}^{3+}$ and TCP may also be related to their adsorption sites on ash, which should be confirmed by X-ray absorption spectroscopy. As a metal ion with higher charges than $\mathrm{Zn}^{2+}, \mathrm{Al}^{3+}$ had a stronger binding capacity to surface negative charges of ash than that of $\mathrm{Zn}^{2+}$. Furthermore, the hydrated radius of $\mathrm{Al}^{3+}(0.45 \mathrm{~nm})$ is also larger than that of $\mathrm{Zn}^{2+}(0.3 \mathrm{~nm})$; hence, $\mathrm{Al}^{3+}$ exhibits stronger inhibition of TCP adsorption.
According to the concept of "soft and hard acids and bases," the hardness of $\mathrm{Ag}^{+}, \mathrm{Zn}^{2+}$, and $\mathrm{Al}^{3+}$ gradually increases, which suggests that $\mathrm{Ag}^{+}$was the strongest in terms of polarization ability. $\mathrm{Ag}^{+}$is highly polarizable and can bind with aromatic organic compounds containing $\pi$-electrons (Chen et al. 2007), resulting in further elevated TCP adsorption by ash. In addition, $\mathrm{Ag}^{+}$has one positive charge and a larger ionic radius than $\mathrm{Zn}^{2+}$ and $\mathrm{Al}^{3+}$; hence, it is relatively easier for $\mathrm{Ag}^{+}$to replace the metal ions (mainly solonetz metal ions such as $\mathrm{Na}^{+}$and $\mathrm{Ca}^{2+}$ ) originally on ash through outer layer complexation reactions (Chen et al. 2007). This will lead to further reduction in the solubility of functional groups on the ash surface and also compress the hydrated ionic radius of these metal ions, thereby reducing the competitive adsorption of water molecules on the ash surface and increasing the adsorption of TCP.

Effect of $\mathrm{Ag}^{+}, \mathrm{Zn}^{2+}$, and $\mathrm{Al}^{3+}$ on desorption of TCP

Obvious desorption hysteresis of TCP from ash was observed with the absence of $\mathrm{Ag}^{+}, \mathrm{Zn}^{2+}$, and $\mathrm{Al}^{3+}$ in solution (Fig. 5). Hysteresis probably resulted due to an entrapped fraction of sorbate that was unable to re-equilibrate when decreased solute

Table 3 Freundlich constants of 2,4,6-TCP adsorbed by ash

\begin{tabular}{lllll}
\hline Adsorbate & $C_{\mathrm{M}}{ }^{2+}(\mathrm{mM})$ & $K_{f}$ & $n$ & $R^{2}$ \\
\hline $\mathrm{TCP}$ & 0 & $21.99 \pm 1.70$ & $0.408 \pm 0.027$ & 0.994 \\
$\mathrm{TCP}+\mathrm{Ag}^{+}$ & 0.01 & $27.01 \pm 2.53$ & $0.424 \pm 0.029$ & 0.979 \\
& 0.05 & $25.34 \pm 2.35$ & $0.443 \pm 0.035$ & 0.985 \\
& 0.10 & $24.25 \pm 2.24$ & $0.455 \pm 0.034$ & 0.975 \\
$\mathrm{TCP}+\mathrm{Zn}^{2+}$ & 0.01 & $20.42 \pm 2.09$ & $0.406 \pm 0.032$ & 0.969 \\
& 0.05 & $19.01 \pm 2.65$ & $0.395 \pm 0.030$ & 0.976 \\
& 0.10 & $17.35 \pm 2.03$ & $0.390 \pm 0.032$ & 0.973 \\
$\mathrm{TCP}+\mathrm{Al}^{3+}$ & 0.01 & $15.46 \pm 2.00$ & $0.394 \pm 0.023$ & 0.959 \\
& 0.05 & $14.11 \pm 2.44$ & $0.390 \pm 0.028$ & 0.966 \\
& 0.10 & $13.98 \pm 2.56$ & $0.385 \pm 0.023$ & 0.972 \\
\hline
\end{tabular}


Fig. 5 Desorption of 2,4,6-TCP form ash: (a) in the absence of metal ions, (b) in the presence of $0.1 \mathrm{mM} \mathrm{Ag}^{+},(\mathbf{c})$ in the presence of $0.1 \mathrm{mM} \mathrm{Zn}^{2+}$, and (d) in the presence of $0.1 \mathrm{mM} \mathrm{Al}^{3+}$
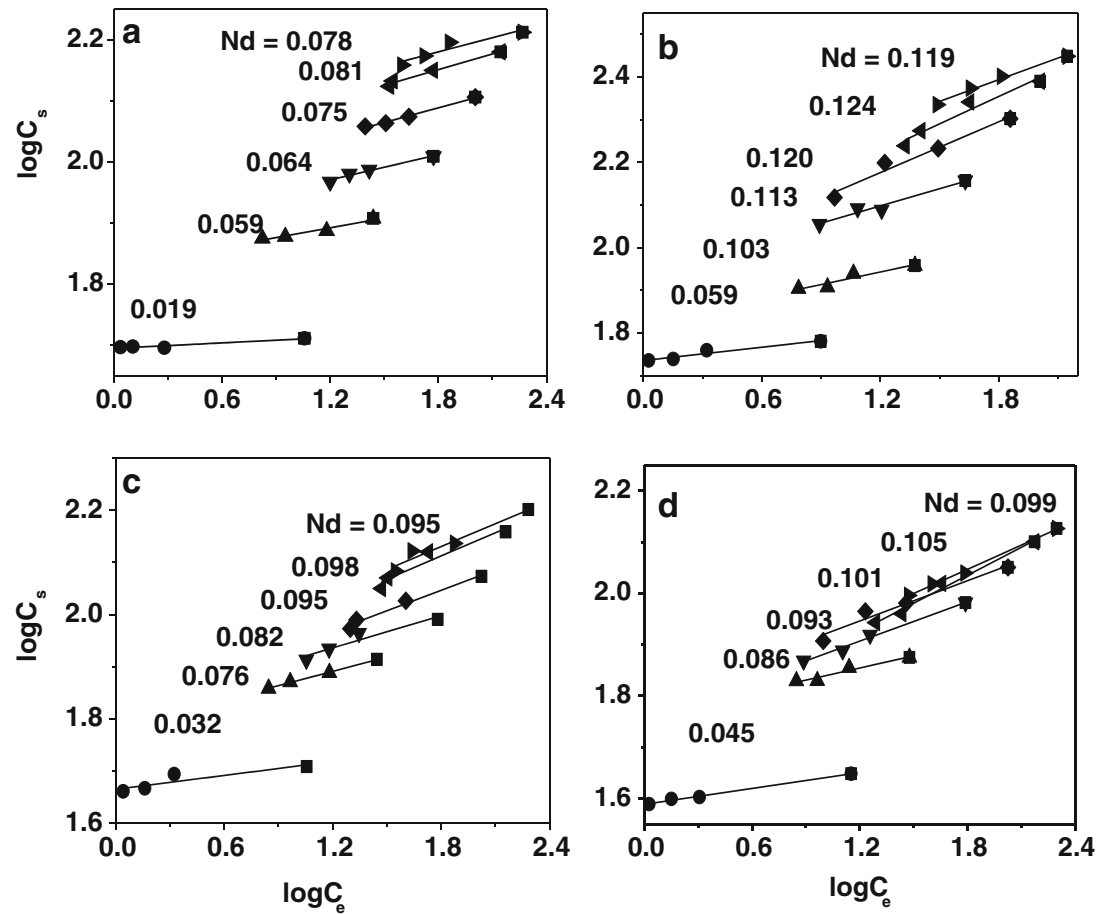

concentrations were achieved during desorption. These unrecoverable and recoverable fractions could potentially be kinetically tracked to final equilibrium or irreversible conditions and the chemical stoichiometry for kinetics and equilibrium could then be established based on the measured functional groups on ash to calculate the reaction sites for TCP. The desorption hysteresis suggested that TCP was adsorbed to a large amount of irreversible adsorption sites related to the relatively more rigid structure of ash (aromatic carbon content was very high; Table 1). This was similar to previous studies on matured organic matter and kerogen, which had more obvious desorption hysteresis (Barriuso et al. 1994).

The desorption hysteresis index (HI), which was defined as the ratio of $N_{\mathrm{d}}$ to $N_{\mathrm{s}}\left(\mathrm{HI}=N_{\mathrm{d}} / N_{\mathrm{s}}\right)$, was used to evaluate the degree of desorption hysteresis (Table 4). When both $N_{\mathrm{d}}$ and $N_{\mathrm{s}}$ values were less than 1 , the smaller the HI value was, the more obvious desorption hysteresis would be. As shown in Fig. 5, the desorption coefficient $N_{\mathrm{d}}$ and HI changed from

Table 4 Hysteresis indexes of 2,4,6-TCP desorption from ash

\begin{tabular}{|c|c|c|c|c|c|c|c|}
\hline \multicolumn{2}{|l|}{ TCP } & \multicolumn{2}{|c|}{$\mathrm{TCP}+\mathrm{Ag}^{+}$} & \multicolumn{2}{|c|}{$\mathrm{TCP}+\mathrm{Zn}^{2+}$} & \multicolumn{2}{|c|}{$\mathrm{TCP}+\mathrm{Al}^{3+}$} \\
\hline$N_{\mathrm{d}}$ & $\mathrm{HI}$ & $N_{\mathrm{d}}$ & $\mathrm{HI}$ & $N_{\mathrm{d}}$ & $\mathrm{HI}$ & $N_{\mathrm{d}}$ & $\mathrm{HI}$ \\
\hline 0.019 & 0.047 & 0.059 & 0.129 & 0.032 & 0.082 & 0.045 & 0.116 \\
\hline 0.059 & 0.146 & 0.103 & 0.226 & 0.076 & 0.194 & 0.086 & 0.223 \\
\hline 0.064 & 0.158 & 0.113 & 0.248 & 0.082 & 0.210 & 0.093 & 0.241 \\
\hline 0.075 & 0.185 & 0.120 & 0.263 & 0.095 & 0.243 & 0.101 & 0.262 \\
\hline 0.081 & 0.200 & 0.124 & 0.272 & 0.098 & 0.251 & 0.105 & 0.272 \\
\hline 0.078 & 0.193 & 0.119 & 0.261 & 0.095 & 0.243 & 0.099 & 0.257 \\
\hline
\end{tabular}

small to large as TCP concentration increased, i.e., desorption became relatively easier. This implied that TCP adsorbed mainly on these high-energy adsorption sites, and desorption was difficult at a low concentration of TCP. As TCP concentration further increased, parts of TCP could only be adsorbed on the low-energy adsorption sites, which was relatively easy for desorption.

Desorption hysteresis of TCP from ash was also observed quite clearly with the presence of $\mathrm{Ag}^{+}, \mathrm{Zn}^{2+}$, and $\mathrm{Al}^{3+}$ in solution (Fig. 5). In addition, the HI values increased with the presence of $\mathrm{Ag}^{+}, \mathrm{Zn}^{2+}$, and $\mathrm{Al}^{3+}$ in solution, which suggested that the addition of $\mathrm{Ag}^{+}, \mathrm{Zn}^{2+}$, and $\mathrm{Al}^{3+}$ could promote TCP desorption from ash. It implied that metal cations occupied part of the high-energy sites of previously adsorbed TCP, demonstrating desorption hysteris for TCP.

\section{Conclusions}

Adsorption studies revealed the underlying mechanisms responsible for the effects of metal cations $\left(\mathrm{Ag}^{+}, \mathrm{Zn}^{2+}\right.$, and $\left.\mathrm{Al}^{3+}\right)$ on TCP adsorption onto, and desorption from, wheat ash, implying that the environmental fate of metal cations and TCP in the metal-TCP system is quite different from that of either metals or TCP alone. TCP showed obvious desorption hysteresis, and the presence of $\mathrm{Ag}^{+}, \mathrm{Zn}^{2+}$, and $\mathrm{Al}^{3+}$ promoted desorption of TCP from ash. The presence of $\mathrm{Ag}^{+}$increased TCP adsorption and was ascribed to its ability to reduce the competitive adsorption of water molecules on the ash surface by replacing the original metal ions, such as $\mathrm{Na}^{+}$and $\mathrm{Ca}^{2+}$, 
and compressing the hydrated ionic radius of these metal ions. In addition, $\mathrm{Ag}^{+}$could bind with aromatic organic compounds containing $\pi$-electrons, resulting in a further increase of TCP adsorption by ash. The presence of $\mathrm{Zn}^{2+}$ and $\mathrm{Al}^{3+}$ reduced TCP adsorption onto ash and was ascribed to a partial overlapping of adsorption groups for TCP and $\mathrm{Zn}^{2+}$ and $\mathrm{Al}^{3+}$. Such information helps our understanding of real environmental processes relating to metals and aromatics in the soil-water environment.

Acknowledgements This work was funded by the National Natural Science Foundation of China (grant numbers: 21207157, 41071308, and 21277159) and the Research Institute of Subtropical Forestry, Chinese Academy of Forestry (RISF 2013001).

\section{References}

Barriuso E, Laird DA, Koskinen WC, Dowdy RH (1994) Atrazine desorption from smectites. Soil Sci Soc Am J 58:1632-1638

Benguella B, Benaissa H (2002) Cadmium removal from aqueous solutions by chitin: kinetic and equilibrium studies. Water Res 36:2463-2474

Cea M, Seaman JC, Jara AA, Mora ML, Diez MC (2005) Describing chlorophenol sorption on variable-charge soil using the triple-layer model. J Colloid Interface Sci 292:171-178

Chaliha S, Bhattacharyya KG (2008) Catalytic wet oxidation of 2chlorophenol, 2,4-dichlorophenol and 2,4,6-trichlorophenol in water with Mn(II)-MCM41. Chem Eng J 139:575-588

Chen JY, Zhu DQ, Sun C (2007) Effect of heavy metals on the sorption of hydrophobic organic compounds to wood charcoal. Environ Sci Technol 41:2536-2541

Chen GC, Shan XQ, Wang YS, Wen B, Pei ZG, Xie YN, Liu T, Pignatello JJ (2009) Adsorption of 2,4,6-trichlorophenol onto multi-walled carbon nanotubes as affected by $\mathrm{Cu}$ (II). Water Res 43:2409-2418

Chun Y, Sheng G, Chiou CT, Xing B (2004) Compositions and sorptive properties of crop residue-derived chars. Environ Sci Technol 38: 4649-4655

Daughney CJ, Fein JB (1997) Aqueous complexation of cadmium, lead, and copper by 2,4,6-trichlorophenolate and pentachlorophenolate. Geochim Cosmochim Acta 61:719-729

Dilip HL, Indra MM, Indra DM (2006) Removal of pyridine from aqueous solution by adsorption on bagasse fly ash. Ind Eng Chem Res 45:3934-3943

Ho YS, McKay G (1998) Sorption of dye from aqueous solution by pit. Chem Eng J 70:115-124
Keith LH, Telliard WA (1979) ES\&T special report: priority pollutants: part I-a perspective view. Environ Sci Technol 13:416-423

Kung KHS, McBride MB (1991) Bonding of chlorophenols on iron and aluminum oxides. Environ Sci Technol 25:702-709

Mueller JG, Chapmanm PJ, Pritchard PH (1989) Creosote-contaminated sites. Their potential for bioremediation. Environ Sci Technol 23: $1197-1201$

Naidu R, Sumner ME, Harter RD (1998) Adsorption of heavy metals in strongly weathered soils, an overview. Environ Geochem Health 20: $5-9$

Seco-Reigosa N, Peña-Rodríguez S, Nóvoa-Muñoz JC, Arias-Estévez M, Fernández-Sanjurjo MJ, Álvarez-Rodríguez E, Núñez-Delgado A (2013) Arsenic, chromium and mercury removal using mussel shell ash or a sludge/ashes waste mixture. Environ Sci Pollut Res 20(4): 2670-2678

Shah B, Mistry C, Shah A (2013) Seizure modeling of Pb (II) and Cd (II) from aqueous solution by chemically modified sugarcane bagasse fly ash: isotherms, kinetics, and column study. Environ Sci Pollut Res 20(4):2193-2209

Sprovieri M, Feo ML, Prevedello L, Manta DS, Sammartino S, Tamburrino S, Marsella E (2007) Heavy metals, polycyclic aromatic hydrocarbons and polychlorinated biphenyls in surface sediments of the Naples harbor (southern Italy). Chemosphere 67:998-1009

Srivastava VC, Swamy MM, Mall ID, Prasad B, Mishra IM (2005) Adsorptive removal of phenol by bagasse fly ash and activated carbon: Equilibrium, kinetics and thermodynamics. Colloids Surf A 272:89-104

Toth J, Milham PJ, Kaldor CJ (1999) Decreased phytotoxicity of diuron applied over ash of recently burned kangaroo grass. Plant Prot Q 14: $151-154$

Wang XP, Shan XQ, Luo L, Zhang SZ, Wen B (2005) Sorption of 2,4,6trichlorophenol in model humic acid-clay systems. J Agric Food Chem 53:3548-3555

Wang YS, Feng MH, Shan XQ, Chen GC, Pei ZG, Wen B, Liu T, Xie YN, Owens G (2009) Effects of copper, lead and cadmium on the sorption of 2,4,6-trichlorophenol onto and desorption from wheat ash and two humic acids. Environ Sci Technol 43:5726-5731

Wang YS, Pei ZG, Shan XQ, Chen GC, Zheng LR, Zhang J, Xie YN (2011) Effects of metal cations on sorption-desorption of pnitrophenol onto wheat ash. J Environ Sci 23(1):112-118

Wightman P, Fein JB (1999) Experimental study of 2,4,6-trichlorophenol and pentachlorophenol solubilities in aqueous solutions: derivation of a speciation-based chlorophenol solubility model. Appl Geochem 14:319-331

Yang YN, Sheng GY (2003) Enhanced pesticide sorption by soils containing particulate matter from crop residue burns. Environ Sci Technol 37:3635-3639

Zhou WM, Fu DQ, Sun ZG (1991) Determination of black list of China's priority pollutants in water. Res Environ Sci 4:912-915 